\title{
A Novel Liquid Crystal-Filled, Dual-Core Photonic Crystal Fiber Polarization Beam Splitter Covering the E + S + C + L + U Communication Band
}

\author{
Yuwei Qu ${ }^{1}$, Ying Han ${ }^{2,3, *}$, Jinhui Yuan ${ }^{1,4}$, Xian Zhou ${ }^{4}$, Binbin Yan ${ }^{1}$, Kuiru Wang ${ }^{1}$, Xinzhu Sang ${ }^{1}$ \\ and Chongxiu Yu ${ }^{1}$ \\ 1 State Key Laboratory of Information Photonics and Optical Communications, Beijing University of Posts and \\ Telecommunications, Beijing 100876, China; quyuwei@bupt.edu.cn (Y.Q.); yuanjinhui81@bupt.edu.cn (J.Y.); \\ yanbinbin@bupt.edu.cn (B.Y.); krwang@bupt.edu.cn (K.W.); xzsang@bupt.edu.cn (X.S.); \\ cxyu@bupt.edu.cn (C.Y.) \\ 2 School of Information Science and Engineering, Yanshan University, Qinhuangdao 066004, China \\ 3 Key Laboratory for Special Fiber and Fiber Sensor of Hebei Province, Qinhuangdao 066004, China \\ 4 Research Center for Convergence Networks and Ubiquitous Services, University of Science \& Technology \\ Beijing (USTB), Beijing 100083, China; zhouxian219@ustb.edu.cn \\ * Correspondence: hanying2020@ysu.edu.cn
}

Citation: Qu, Y.; Han, Y.; Yuan, J.; Zhou, X.; Yan, B.; Wang, K.; Sang, X.; Yu, C. A Novel Liquid Crystal-Filled, Dual-Core Photonic Crystal Fiber Polarization Beam Splitter Covering the $\mathrm{E}+\mathrm{S}+\mathrm{C}+\mathrm{L}+\mathrm{U}$ Communication Band. Photonics 2021, 8, 461. https:// doi.org/10.3390/photonics8110461

Received: 19 August 2021

Accepted: 19 October 2021

Published: 21 October 2021

Publisher's Note: MDPI stays neutral with regard to jurisdictional claims in published maps and institutional affiliations.

Copyright: (c) 2021 by the authors. Licensee MDPI, Basel, Switzerland. This article is an open access article distributed under the terms and conditions of the Creative Commons Attribution (CC BY) license (https:// creativecommons.org/licenses/by/ $4.0 /)$.

\begin{abstract}
This paper proposes a novel liquid crystal-filled, dual core photonic crystal fiber polarization beam splitter (LC-DC-PCF PBS) based on the coupled mode theory of DC-PCF. The mode birefringence of odd and even modes, coupling lengths (CLs) of the X-polarization (X-pol) and Ypolarization (Y-pol), and the corresponding coupling length ratio (CLR) of the proposed LC-DC-PCF PBS filled without LC E7 and with LC E7 are compared. The change rules of the CLs of the X-pol and Y-pol and CLR of the proposed LC-DC-PCF with wavelengths for different cladding microstructure parameters were investigated. The relationships between the X-pol and Y-pol normalized output powers in core A of the proposed LC-DC-PCF PBS and the propagation length at the wavelength of $1.604 \mu \mathrm{m}$ are discussed. Finally, by studying the change of extinction ratio $(E R)$ with wavelength, the LC-DC-PCF PBS ER of 60.3 and $72.2 \mathrm{~dB}$ at wavelengths 1.386 and $1.619 \mu \mathrm{m}$ are achieved, respectively. The final splitting length $\left(L_{S}\right)$ is $94 \mu \mathrm{m}$, and the splitting bandwidth is $349 \mathrm{~nm}(1.352 \sim 1.701 \mu \mathrm{m})$, covering the whole of the $\mathrm{E}+\mathrm{S}+\mathrm{C}+\mathrm{L}+\mathrm{U}$ communication bands. The proposed LC-DC-PCF PBS has good beam-splitting performance, such as ultra-short $L_{\mathrm{S}}$ and ultra-wide splitting bandwidth, with potential applications in laser, sensing, and communication systems.
\end{abstract}

Keywords: liquid crystal; dual-core photonic crystal fiber; polarization beam splitter; extinction ratio

\section{Introduction}

In the late 1990s, J.C. Knight et al. proposed and successfully fabricated the first photonic crystal fiber (PCF), whose cladding was composed of micron-sized air holes arranged according to certain rules [1-3]. In the following 20 years, due to the flexible cladding microstructure of PCF and the maturity of fiber post-processing technology, the PCF has experienced incredible development in various fields of optics and photonics [4-10]. Especially after all six optical fiber communication windows O (1260-1360 nm), E (1360-1460 nm), S (1460-1530 nm), C (1530-1565 nm), L (1565-1625 nm), and U (1625-1675 nm) are proposed, PCF has more significant advantages in the field of multi window optical fiber communication.

In recent years, researchers worldwide have conducted a great deal of research on the dual-core photonic crystal fiber (DC-PCF) [11-15]. A large number of studies have shown that a polarization beam splitter (PBS) with excellent performance can be obtained by using the coupled mode theory of DC-PCF and fiber post-processing technology, such as filling with liquid crystal (LC), liquid, or precious metal materials in some fixed air holes of DC-PCF [16-23]. However, the commonly used precious metal filling materials 
are generally gold or silver materials, which are expensive, and the deposition process is complex. Complex methods such as high-pressure chemical vapor deposition and radio frequency magnetron sputtering are usually needed. Compared with gold and silver materials, LC or liquid filling materials have a lower price and simpler filling process, so many researchers have favored them in recent years. In 2016, Wang et al. proposed a DC-PCF PBS filled with LC E7 in all the air holes of the cladding, where the shortest splitting length $\left(L_{S}\right)$ was $890.5 \mu \mathrm{m}$ and the widest splitting bandwidth was $150 \mathrm{~nm}$, which almost covers all the S + C + L communication bands [24]. In 2017, Hagras et al. reported an ultra-compact DC-PCF PBS filled with LC E7 in six big air holes of the cladding. The $L_{S}$ and splitting bandwidth of the DC-PCF PBS were $111.2 \mu \mathrm{m}$ and $88 \mathrm{~nm}$, respectively [25]. In 2018, Younis et al. designed a DC-PCF PBS whose left core was surrounded by LC E7-filled air holes. At wavelengths 1.3 and $1.55 \mu \mathrm{m}$, the splitting bandwidths of the DC-PCF PBS were always $3 \mathrm{~nm}$, and $L_{S}$ were 5.678 and $7.178 \mathrm{~mm}$, respectively [26]. In 2019, Xu et al. proposed a DC-PCF PBS based on rare metal, $\mathrm{Ti}$, and liquid filling in the cladding air holes. The proposed DC-PCF PBS offered an ultra-short length of $83.9 \mu \mathrm{m}$, a high extinction ratio $(E R)$ of $44.05 \mathrm{~dB}$, but the splitting bandwidth was only $32.1 \mathrm{~nm}$ [27]. However, the above-mentioned DC-PCF PBS, LC, or liquid are always filled in multiple air holes, and some DC-PCF PBS also involves filling multiple materials simultaneously or even filling rare metals, which will lead to increased fabrication difficulty and fabrication cost. In addition, it is difficult for the above-mentioned DC-PCF PBS to obtain a shorter $L_{S}$ and a wider splitting bandwidth at the same time.

In this paper, we propose a novel LC-filled DC-PCF (LC-DC-PCF) PBS based on the DC-PCF-coupled mode theory. With the full vector-finite element method (FV-FEM), the differences of the effective refractive indices of odd and even modes, mode birefringence of odd and even modes, coupling length $(C L)$ of the X-polarization (X-pol) and Y-polarization (Y-pol), and coupling length ratio (CLR) in LC-DC-PCF filled without and with LC E7 are simulated and compared. Furthermore, the influences of structural parameters on the CLs of the X-pol and Y-pol and CLR are analyzed. Finally, a LC-DC-PCF PBS with ultra-short $L_{S}(94 \mu \mathrm{m})$ and ultra-wide splitting bandwidth $(349 \mathrm{~nm})$ is obtained, covering the whole of the $\mathrm{E}+\mathrm{S}+\mathrm{C}+\mathrm{L}+\mathrm{U}$ communication bands.

\section{Design of the LC-DC-PCF PBS}

The cross-sectional structure of the proposed LC-DC-PCF PBS is shown in Figure 1. From Figure 1, the most central air hole with the diameter of $d_{1}$ is filled with the LC E7 to obtain high mode birefringence. Near the most central air hole, one air hole is missing in the $\mathrm{X}$-positive direction, and the other is missing in the $\mathrm{X}$-negative direction to form cores $\mathrm{A}$ and $\mathrm{B}$, respectively. To obtain higher mode birefringence, there are three different sizes of air holes around cores $\mathrm{A}$ and $\mathrm{B}$, with diameters of $d_{2}, d_{3}$, and $d_{4}$, respectively. The diameter of the remaining air hole is $d_{5}$, and the distance between any two air holes is $\Lambda$. The proposed LC-DC-PCF is arranged in a triangular lattice, and the background material is silica. A perfectly matched layer (PML) is added to the outermost layer of the proposed LC-DC-PCF to absorb radiation energy [28]. The refractive indices of the silica material and PML are $n_{\text {silica }}$ and $n_{\text {silica }}+0.05$, respectively. In addition, it also can be seen from Figure 1 that cores A and B of the proposed LC-DC-PCF are two symmetrical cores with the same structure.

The refractive index of the $n_{\text {silica }}$ at different wavelengths can be obtained by the Sellmeier equation [29]:

$$
n_{\text {silica }}(\lambda)=\sqrt{1+\frac{\mathrm{A}_{1} \lambda^{2}}{\lambda^{2}-B_{1}^{2}}+\frac{\mathrm{A}_{2} \lambda^{2}}{\lambda^{2}-B_{2}^{2}}+\frac{\mathrm{A}_{3} \lambda^{2}}{\lambda^{2}-B_{3}^{2}}}
$$

where $\lambda$ is the wavelength of the incident light in the free space. Each coefficient in the Sellmeier equation for $n_{\text {silica }}$ can be obtained from Ref. [29]. 


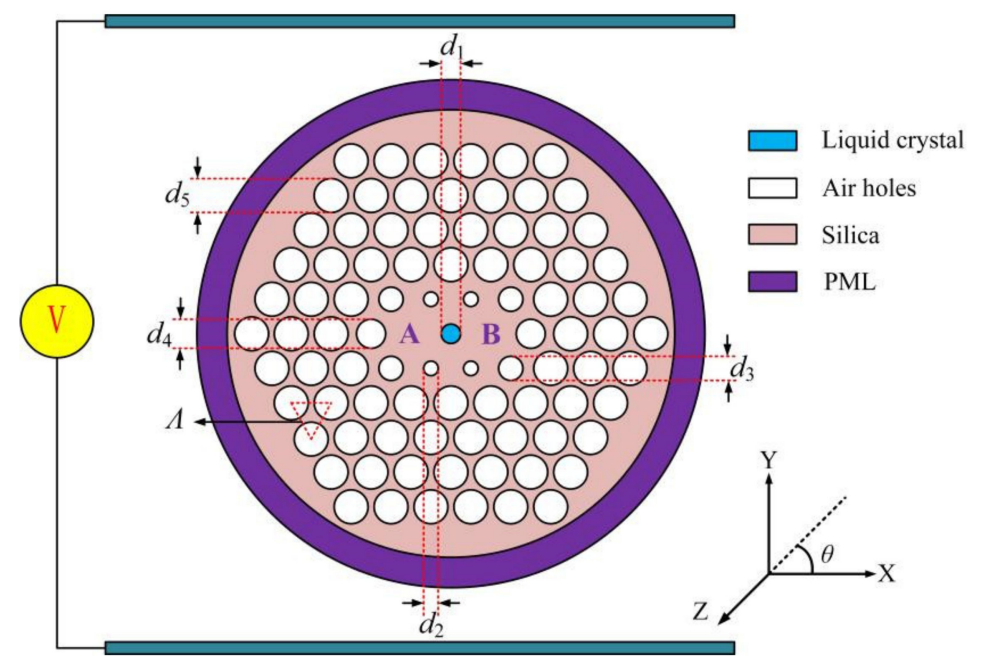

Figure 1. The cross-sectional structure of the proposed LC-DC-PCF PBS.

The ordinary refractive index $n_{\mathrm{o}}$ and the extraordinary refractive index $n_{\mathrm{e}}$ of the LC E7 can be described by the extended Cauchy equation [30]:

$$
\begin{aligned}
& n_{\mathrm{o}}=D_{\mathrm{o}}+\frac{E_{\mathrm{o}}}{\lambda^{2}}+\frac{F_{\mathrm{o}}}{\lambda^{4}}, \\
& n_{\mathrm{e}}=D_{\mathrm{e}}+\frac{E_{\mathrm{e}}}{\lambda^{2}}+\frac{F_{\mathrm{e}}}{\lambda^{4}},
\end{aligned}
$$

where $D_{\mathrm{o}}, E_{\mathrm{o}}, F_{\mathrm{o}}, D_{\mathrm{e}}, E_{\mathrm{e}}$, and $F_{\mathrm{e}}$ have some specific functional relationships with temperature, which can be obtained from Ref. [30]. The temperature $T$ is $25^{\circ} \mathrm{C} D_{\mathrm{o}}=1.4994$, $E_{\mathrm{o}}=0.007 \mu \mathrm{m}^{2}, F_{\mathrm{o}}=0.0004 \mu \mathrm{m}^{4}, D_{\mathrm{e}}=1.6933, E_{\mathrm{e}}=0.0078 \mu \mathrm{m}^{2}$, and $F_{\mathrm{e}}=0.0028 \mu \mathrm{m}^{4}$. Here, we set the $T$ to a fixed value of $25^{\circ} \mathrm{C}$.

The relative permittivity of the LC E7 is defined as [31]

$$
\varepsilon_{r}=\left(\begin{array}{ccc}
n_{\mathrm{o}}^{2} \sin ^{2}(\theta)+n_{\mathrm{e}}^{2} \cos ^{2}(\theta) & \left(n_{\mathrm{e}}^{2}-n_{\mathrm{o}}^{2}\right) \cos (\theta) \sin (\theta) & 0 \\
\left(n_{\mathrm{e}}^{2}-n_{\mathrm{o}}^{2}\right) \cos (\theta) \sin (\theta) & n_{\mathrm{o}}^{2} \cos ^{2}(\theta)+n_{\mathrm{e}}^{2} \sin ^{2}(\theta) & 0 \\
0 & 0 & n_{\mathrm{o}}^{2}
\end{array}\right),
$$

where $\theta$ is the angle between the direction vector of the LC E7 material and the X-axis. $\theta$ can be controlled by an external electric field, such as placing the proposed LC-DCPCF between two electrodes, as shown in Figure 1. The LC E7 molecules can usually be arranged in three forms by modulating the external electric field: the long axis of the LC E7 molecules is parallel to the $X$-axis, that is, $\theta$ is equal to $0^{\circ}$. $\theta$ between the long axis of the LC E7 molecule and the $\mathrm{X}$-axis is $45^{\circ}$. The long axis of the LC E7 molecule is perpendicular to the $\mathrm{X}$-axis; that is, $\theta$ is equal to $90^{\circ}$. Here, we set $\theta$ to the most commonly used fixed value of $90^{\circ}$ [31]. as [32]

The even mode birefringence $\left(B_{\mathrm{e}}\right)$ and odd mode birefringence $\left(B_{\mathrm{o}}\right)$ can be defined

$$
\begin{gathered}
B_{\mathrm{e}}=\left|n_{\text {even }}^{\mathrm{X}}-n_{\text {even }}^{\mathrm{Y}}\right|, \\
B_{\mathrm{O}}=\left|n_{\text {odd }}^{\mathrm{X}}-n_{\text {odd }}^{\mathrm{Y}}\right|,
\end{gathered}
$$

where $n_{\text {even }}^{\mathrm{X}}, n_{\text {even }}^{\mathrm{Y}}, n_{\mathrm{odd}}^{\mathrm{X}}$, and $n_{\text {odd }}^{\mathrm{Y}}$ represent the effective refractive indices of the even and odd modes of the $X$-pol and Y-pol, respectively.

Because the DC structures of DC-PCF are completely symmetrical and the medium distribution is the same, the dual-core mode coupling equation can be expressed as [33]

$$
\frac{d a_{1}(z)}{d z}=i \beta a_{1}(z)+i K a_{2}(z)
$$




$$
\frac{d a_{2}(z)}{d z}=i \beta a_{2}(z)+i K a_{1}(z),
$$

where $\beta$ is the propagation constant of the $D C, K$ is the coupling coefficient of the dual core, and $z$ represents the transmission direction and distance.

By setting a series of initial condition parameters, combined with the fact that the DC-PCF has even mode and odd mode in the X-pol and Y-pol, respectively, the mode coupling equation is solved, and the CLs of the DC-PCF can be obtained.

The CLs of the X-pol and Y-pol of the LC-DC-PCF PBS can be calculated as [34]

$$
\begin{aligned}
& C L_{\mathrm{X}}=\frac{\lambda}{2 \mid\left(n_{\mathrm{even}}^{\mathrm{X}}-n_{\mathrm{odd}}^{\mathrm{X}}\right){ }^{\prime}}, \\
& C L_{\mathrm{Y}}=\frac{\lambda}{2\left|\left(n_{\mathrm{even}}^{\mathrm{Y}}-n_{\mathrm{odd}}^{\mathrm{Y}}\right)\right|^{\prime}},
\end{aligned}
$$

where $C L_{X}$ and $C L_{Y}$ represent the $C L$ of the X-pol and Y-pol, respectively.

The CLR can be calculated by [35]

$$
C L R=\frac{C L_{Y}}{C L_{\mathrm{X}}},
$$

According to the previous studies, when the optimal $C L R=2$ or $1 / 2$ and the $C L_{X}$ and $C L_{Y}$ are shorter, it is easier for the PBS to have the shortest $L_{S}$ [36].

Because cores A and B of the proposed LC-DC-PCF have symmetrical and identical structures, only incident light from cores A or B should be considered [37]. Here, we assume that the incident light is incident from core A. The normalized output power $\left(P_{\text {out }}\right)$ in the X-pol and Y-pol in the core A can be described as [38]

$$
P_{\text {out, } \mathrm{A}}^{\mathrm{X}, \mathrm{Y}}=P_{\mathrm{in}} \cos ^{2}\left(\frac{\pi}{2} \frac{L_{\mathrm{P}}}{C L_{\mathrm{X}, \mathrm{Y}}}\right),
$$

where $P_{\text {in }}$ is the input power of the incident light, and $L_{P}$ is the propagation length of the LC-DC-PCF PBS. According to Equation (10), $L_{P}$ will change periodically. According to previous studies, the shortest $L_{\mathrm{P}}$ is also the shortest $L_{\mathrm{S}}$ [39].

The $E R$ of the core A can be calculated as [40].

$$
E R_{\mathrm{A}}=10 \log _{10} \frac{P_{\text {out }, \mathrm{A}}^{\mathrm{X}}}{P_{\text {out }, \mathrm{A}}^{\mathrm{Y}}},
$$

For the PBS, the $E R$ is a significant indicator with which to judge and characterize the performance of the PBS. In practical application, when the $E R$ reaches $20 \mathrm{~dB}$, the power of the polarization light is 100 times that of the other, which is enough to separate two orthogonal polarization lights. Generally speaking, the wavelength range with the $E R$ greater than $20 \mathrm{~dB}$ is the splitting bandwidth of the PBS [41].

\section{Simulation Results}

The initial structural parameters of the LC-DC-PCF are set as follows: $d_{1}=0.85 \mu \mathrm{m}$, $d_{2}=1.00 \mu \mathrm{m}, d_{3}=1.50 \mu \mathrm{m}, d_{4}=1.60 \mu \mathrm{m}, d_{5}=1.65 \mu \mathrm{m}$, and $\Lambda=2.10 \mu \mathrm{m}$. The relationships between the effective refractive indices of the X-pol and Y-pol even and odd modes of the LC-DC-PCF and the wavelength are shown in Figure 2a,b when the LC-DC-PCF is filled without and with LC E7, respectively. From Figure 2a, when the LC-DC-PCF is filled without LC E7, the effective refractive indices of the X-pol and Y-pol even and odd modes decrease with the increase in wavelength. The effective refractive index curves of the X-pol and Y-pol even modes are very close, and those of the X-pol and Y-pol odd modes are virtually overlapped. In other words, the effective refractive index differences between the X-pol and Y-pol even modes or X-pol and Y-pol odd modes are very small. Therefore, 
the values of the $B_{\mathrm{e}}$ and $B_{\mathrm{o}}$ are also very small. From Figure $2 \mathrm{~b}$, when the LC-DC-PCF is filled with LC E7, the effective refractive indices of the X-pol and Y-pol even and odd modes decrease with the increase in wavelength. This change trend is similar to that filled without LC E7. The effective refractive index curves of the X-pol and Y-pol odd modes are also nearly overlapped. However, the effective refractive index values of the $\mathrm{X}$-pol and Y-pol even modes have an obvious change, respectively. In other words, the effective refractive index difference between X-pol and Y-pol odd modes is also very small, but the effective refractive index difference between X-pol and Y-pol even modes is a larger value. Therefore, the $B_{\mathrm{o}}$ will still be small, but the $B_{\mathrm{e}}$ will be large. The $B_{\mathrm{e}}$ and $B_{\mathrm{o}}$ of the LC-DC-PCF are shown in Figure 3 when the LC-DC-PCF is filled without and with LC E7. From Figure 3 , the $B_{\mathrm{e}}$ and $B_{\mathrm{o}}$ are kept very small with the wavelength increase when the LC-DC-PCF is filled without LC E7. When the LC-DC-PCF is filled with LC E7, the $B_{\mathrm{o}}$ still keeps a small value, but the $B_{\mathrm{e}}$ increases. $B_{\mathrm{e}}$ varies from $6.7 \times 10^{-3}$ to $1.2 \times 10^{-2}$ in the wavelength range of $1.3 \sim 1.8 \mu \mathrm{m}$, which is a relatively large mode birefringence compared with many previous studies. According to the above analysis, a large $B_{\mathrm{e}}$ can be introduced by filling LC E7 in the most central air hole.
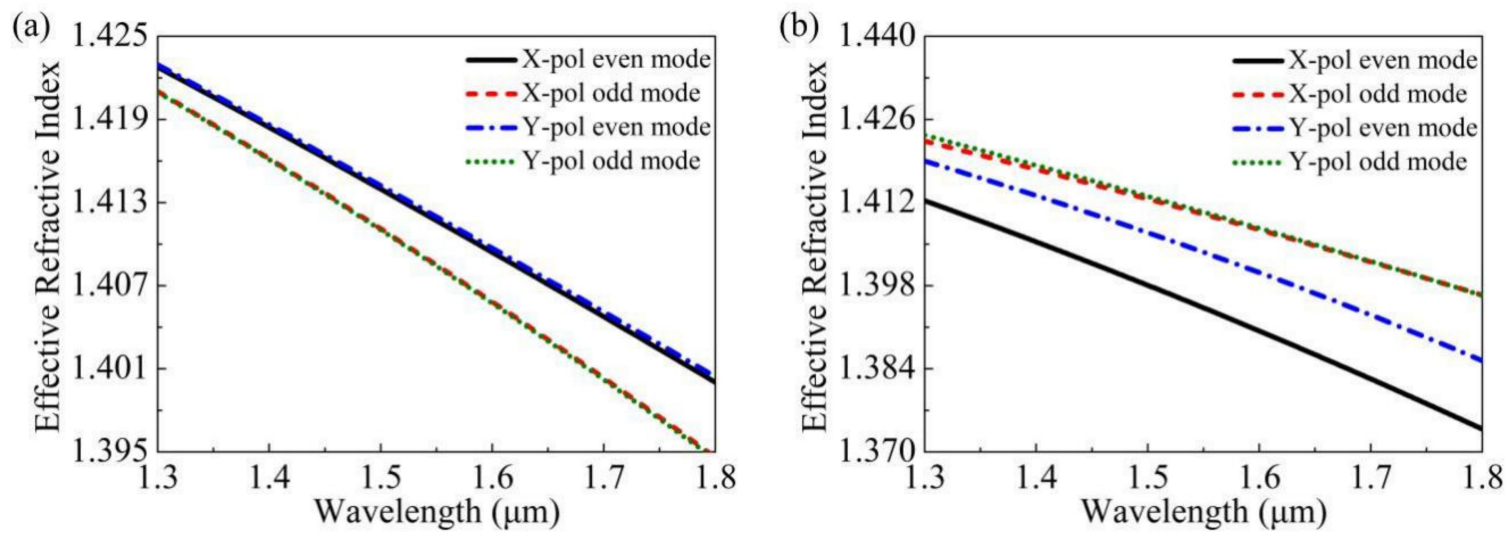

Figure 2. The effective refractive indices of the X-pol and Y-pol even and odd modes of the LC-DC-PCF when the LC-DC-PCF is filled (a) without and (b) with LC E7, respectively.

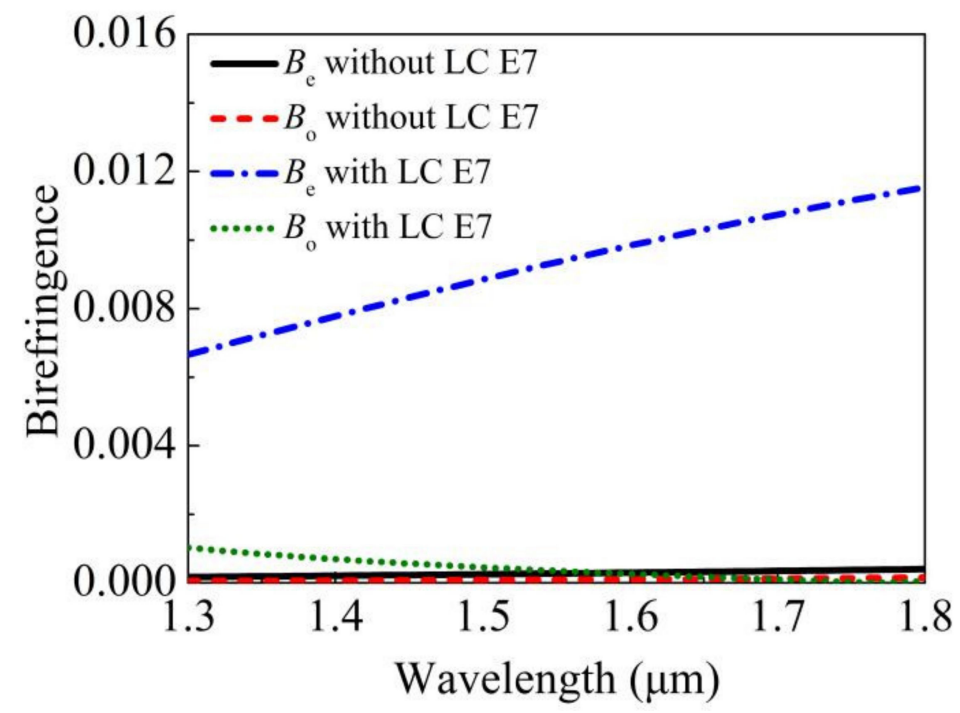

Figure 3. The $B_{\mathrm{e}}$ and $B_{\mathrm{o}}$ of the LC-DC-PCF when the LC-DC-PCF is filled without and with LC E7.

To further explain the above phenomenon, Figure 4a,b shows the mode field distributions of the X-pol and Y-pol even and odd modes at wavelengths 1.3 and $1.8 \mu \mathrm{m}$, respectively, when the LC-DC-PCF is filled with LC E7. From Figure 4a,b, when the LC- 
DC-PCF is filled with LC E7, the mode field energies of the X-pol and Y-pol odd modes are mainly distributed in cores $\mathrm{A}$ and $\mathrm{B}$ at wavelengths 1.3 and $1.8 \mu \mathrm{m}$, respectively. According to previous work, this is the same as that of conventional DC-PCF. However, no matter at 1.3 or $1.8 \mu \mathrm{m}$, most of the mode field energy of the X-pol and Y-pol even modes is still distributed in cores $A$ and $B$, but a small part is distributed in the most central air hole filled with LC E7. This is also why $B_{\mathrm{e}}$ is larger when the LC E7 is filled into the most central air hole. Therefore, the most central air hole filled with LC E7 can be regarded as a modulation core. At wavelengths 1.3 and $1.8 \mu \mathrm{m}$, the energy percentages of mode field energy of the $\mathrm{X}$-pol and Y-pol even modes transmitted in the modulation core are $6.79 \%, 1.23 \%$, and $6.96 \%, 3.46 \%$, respectively. It can be seen from Figure $4 \mathrm{a}, \mathrm{b}$ that the energy transmitted in cores $\mathrm{A}$ and $\mathrm{B}$ is much greater than that in modulation core. Therefore, the $C L_{X}, C L_{Y}$, and CLR can be analyzed using the DC-PCF coupling mode theory [42] and Equations (9)-(11).

(a) $\lambda=1.3 \mu \mathrm{m}$

(b) $\lambda=1.8 \mu \mathrm{m}$

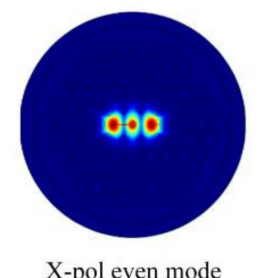

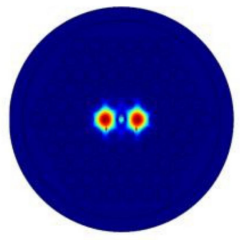

Y-pol even mode

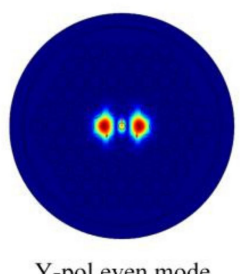

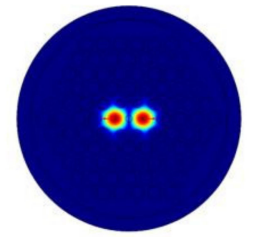

X-pol odd mode

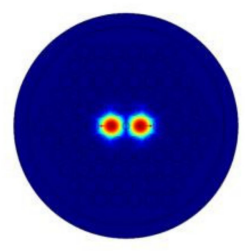

X-pol odd mode

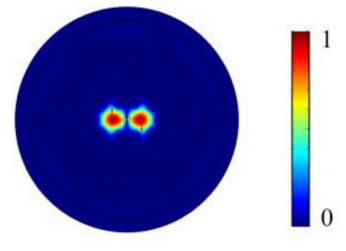

Y-pol odd mode

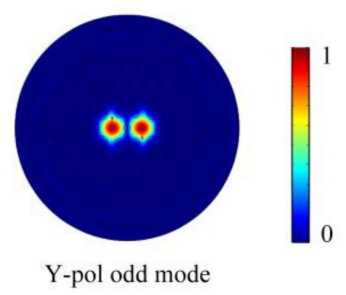

Figure 4. The mode field distribution of the X-pol and Y-pol even and odd modes at (a) $1.3 \mu \mathrm{m}$ and (b) $1.8 \mu \mathrm{m}$ when the LC-DC-PCF is filled with LC E7.

Figure $5 \mathrm{a}, \mathrm{b}$ shows the $C L_{X}, C L_{Y}$, and CLR of the LC-DC-PCF when the LC-DC-PCF is filled without and with LC E7, respectively. From Figure 5a, when the LC-DC-PCF is filled without LC E7, the CLX,CLY, and CLR decrease approximately linearly with the wavelength increase. However, the difference between $C L_{X}$ and $C L_{Y}$ is small, which leads to smaller values and smaller changes of CLR. This phenomenon can be deduced from the results shown in Figure 2a and Equations (9)-(11). In addition, at a wavelength of $1.8 \mu \mathrm{m}$, the minimum values of the $C L_{X}$ and $C L_{Y}$ are 151 and $167 \mu \mathrm{m}$, respectively. At wavelengths of 1.3 and $1.8 \mu \mathrm{m}$, the largest and smallest CLR are 1.102 and 1.125 , respectively. From Figure 5b, when the LC-DC-PCF is filled with LC E7, although the CLX and CLY decrease approximate linearly with the increase in wavelength, the difference between the CLX and $C L_{Y}$ decreases gradually. However, the minimum difference is also much larger than when the LC-DC-PCF is filled without LC E7. With the increase in wavelength, CLR has a trend of increasing first and then decreasing. This is because the introduction of the modulation core produces a large $B_{\mathrm{e}}$, leading to a large change in the effective refractive index of the $X$-pol and Y-pol even modes, which leads to the corresponding change of the $C L_{X}, C L_{Y}$, and $C L R$. At $1.3 \mu \mathrm{m}$, the maximum values of the $C L_{X}$ and $C L_{Y}$ are 65 and $148 \mu \mathrm{m}$, respectively. Additionally, in the wavelength range of $1.3 \sim 1.8 \mu \mathrm{m}$, the minimum and maximum values of CLR are 2.057 and 2.395, respectively. Therefore, when the LC-DC-PCF is filled with LC E7, the maximum $C L_{X}$ and $C L_{Y}$ are smaller than the minimum $C L_{X}$ and $C L_{Y}$ when the LC-DC-PCF is filled without LC E7, and the CLR value in the range of $1.3 \sim 1.8 \mu \mathrm{m}$ is closer to the optimal $C L R=2$. In other words, the LC-DC-PCF is filled with LC E7; if CLR = 2 is obtained at a certain wavelength in the communication band and the $C L_{X}$ and $C L_{Y}$ have a small value, the proposed LC-DC-PCF PBS may obtain better beam splitting characteristics. 
Therefore, in the following, we will discuss the change rule of the $C L_{X}, C L_{Y}$, and CLR of the proposed LC-DC-PCF with the change of each structural parameter.
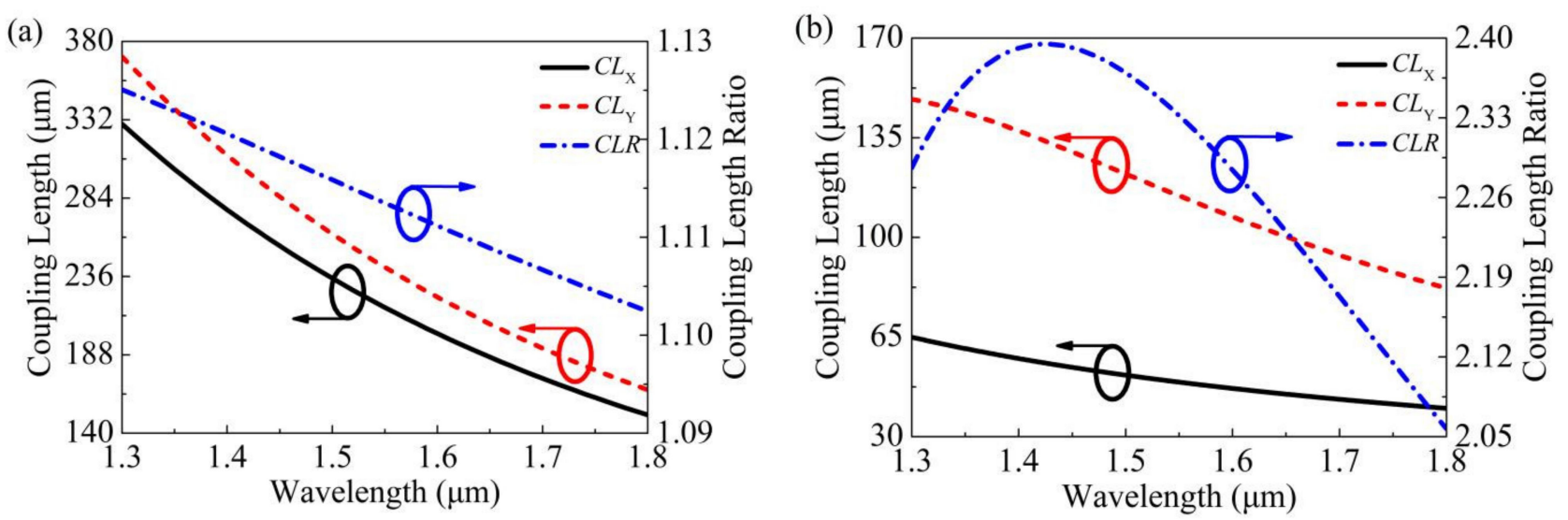

Figure 5. The $C L_{X}, C L_{Y}$, and CLR of the LC-DC-PCF when the LC-DC-PCF is filled (a) without and (b) with LC E7, respectively.

The change rules of the $C L_{X}, C L_{Y}$, and $C L R$ of the proposed LC-DC-PCF with wavelengths for different $d_{1}$ are shown in Figure 6a-c. From Figure 6a, when $d_{1}$ increases from 0.65 to $1.05 \mu \mathrm{m}$, the $C L_{X}$ increases gradually in the whole wavelength range of $1.3 \sim 1.8 \mu \mathrm{m}$. However, the increased extent of the $C L_{X}$ at a short wavelength is larger than that at a long wavelength. From Figure $6 \mathrm{~b}$, when $d_{1}$ increases from 0.65 to $0.75 \mu \mathrm{m}$, the $C L_{Y}$ also increases gradually in the whole wavelength range of 1.3 1.8 $\mu \mathrm{m}$. However, when $d_{1}$ increases from $0.75 \sim 0.95 \mu \mathrm{m}$, the $C L_{Y}$ decreases gradually at the short wavelength, and the decreasing range is larger, while the $C L_{Y}$ increases gradually at the long wavelength and the increasing range is smaller. When $d_{1}$ increases from 0.95 to $1.05 \mu \mathrm{m}$, the $C L_{Y}$ decreases gradually in the wavelength range of $1.3 \sim 1.8 \mu \mathrm{m}$, while the $C L_{Y}$ has a larger decrease at a short wavelength and a smaller decrease at a long wavelength. On the whole, the change range of the $C L_{Y}$ in the short wavelength is larger than that in the long wavelength when $d_{1}$ increases from 0.75 to $1.05 \mu \mathrm{m}$. From Figure $6 \mathrm{c}$, the $C L R$ also increases in the whole wavelength range of $1.3 \sim 1.8 \mu \mathrm{m}$ with the increase in $d_{1}$ from 0.65 to $0.75 \mu \mathrm{m}$, then decreases in the short wavelength and increases in the long wavelength with the increase in $d_{1}$ from 0.75 to $0.95 \mu \mathrm{m}$, and finally decreases in the whole wavelength range of $1.3 \sim 1.8 \mu \mathrm{m}$ with the increase in $d_{1}$ from 0.95 to $1.05 \mu \mathrm{m}$. On the whole, the $C L R$ occurs to fluctuate in the range from 0.84 to 2.74 . When $d_{1}$ is $0.85 \mu \mathrm{m}$, the minimum and maximum of the CLR are 2.3948 and 2.0568, respectively, and the difference between them is 0.338 .

The change rules of the $C L_{X}, C L_{Y}$, and CLR of the proposed LC-DC-PCF with wavelengths for different $d_{2}$ are shown in Figure 7a-c. From Figure 7a, when $d_{2}$ increases from 0.80 to $1.20 \mu \mathrm{m}$, the $C L_{X}$ maintains a relatively stable increase in the whole wavelength range of $1.3 \sim 1.8 \mu \mathrm{m}$. However, overall, the changing amplitude of the $C L_{X}$ is not very large. From Figure $7 \mathrm{~b}$, when $d_{2}$ increases from 0.80 to $1.00 \mu \mathrm{m}$, the $C L_{Y}$ changes little at the short wavelength but increases steadily at the long wavelength. The $C L_{Y}$ also maintains a relatively stable increase in the whole wavelength range of $1.3 \sim 1.8 \mu \mathrm{m}$ when $d_{2}$ increases from 1.00 to $1.20 \mu \mathrm{m}$. However, on the whole, the changing amplitude of the $C L_{Y}$ is slightly larger than that of the $C L_{X}$. According to the change rule of the $C L_{X}$ and the $C L_{Y}$ with $d_{2}$, the $C L R$ decreases gradually at the short wavelength and increases gradually at the long wavelength when $d_{2}$ increases from 1.00 to $1.20 \mu \mathrm{m}$. In addition, it is found that the larger the $d_{2}$, the smaller the difference between the minimum and maximum CLR. When $d_{2}$ is $1.20 \mu \mathrm{m}$, the minimum and maximum of the CLR are 2.3994 and 2.1534 , respectively, and the difference between them is only 0.246 . 
(a)

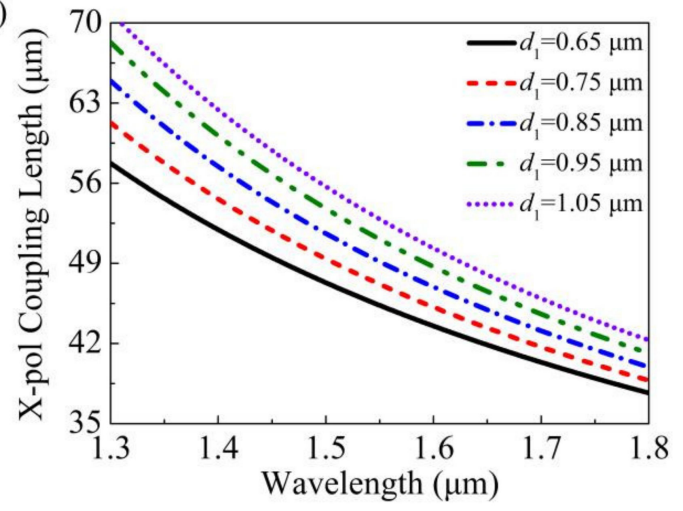

(b)

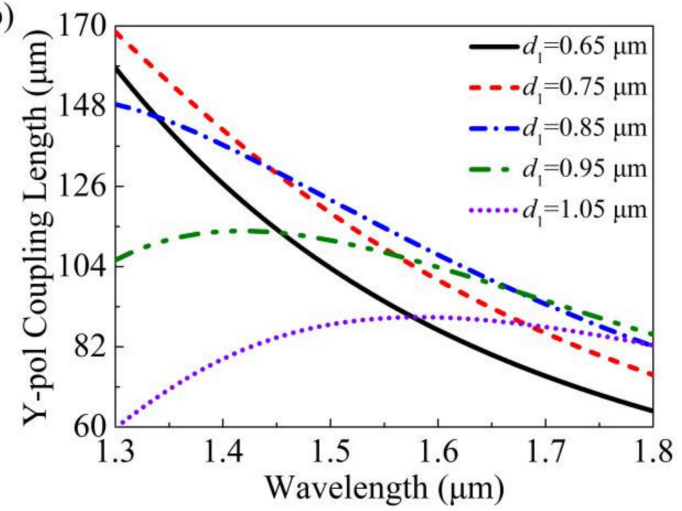

(c)

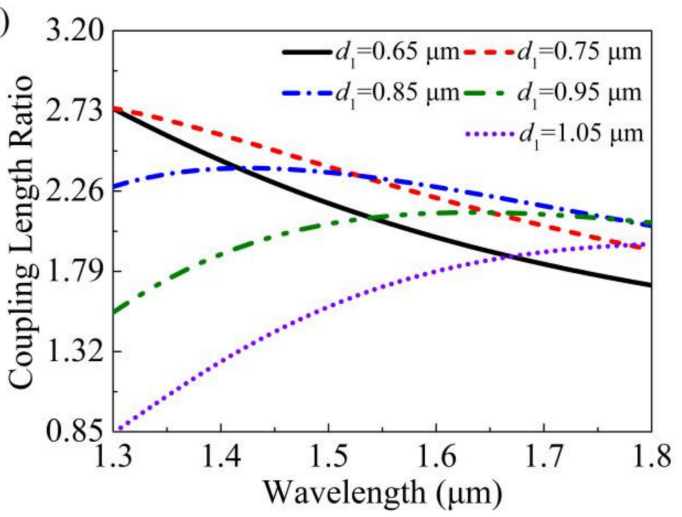

Figure 6. The change rules of the (a) $C L_{X}$, (b) $C L_{Y}$, and (c) CLR of the LC-DC-PCF with wavelengths for different $d_{1}$.

(a)

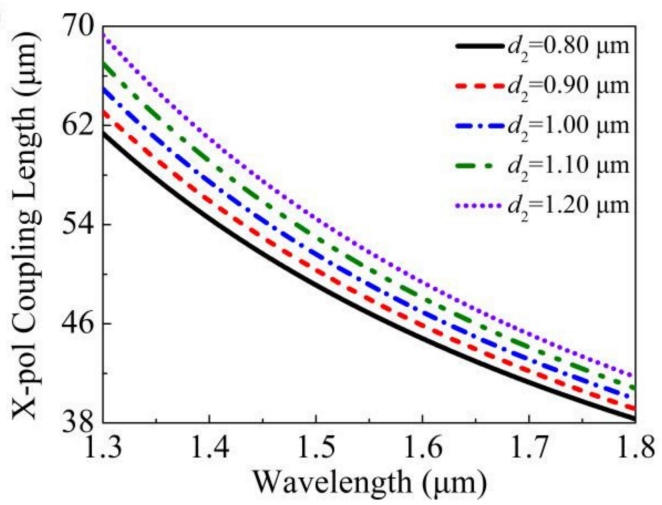

(b)

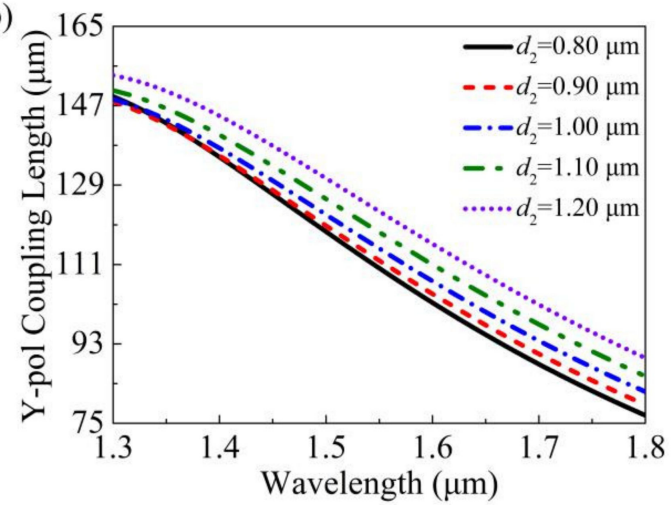

(c)

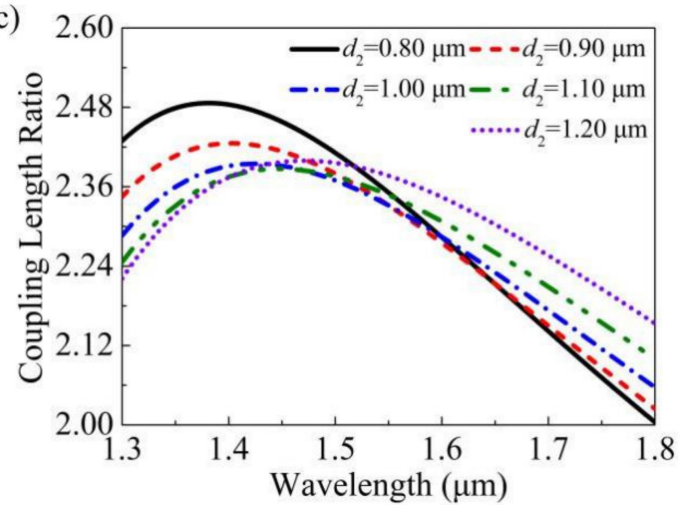

Figure 7. The change rules of the (a) $C L_{X},(\mathbf{b}) C L_{Y}$, and (c) $C L R$ of the LC-DC-PCF with wavelengths Figure 2. 
The change rules of the $C L_{X}, C L_{Y}$, and $C L R$ of the proposed LC-DC-PCF with wavelengths for different $d_{3}$ are shown in Figure 8a-c. From Figure 8a,b, the $C L_{X}$ and $C L_{Y}$ decrease gradually when $d_{3}$ increases from 1.30 to $1.70 \mu \mathrm{m}$ in the whole wavelength range of 1.3 1.8 $\mu \mathrm{m}$. The decreasing amplitude of the $C L_{Y}$ is slightly larger than that of the $C L_{X}$. Thus, it can be seen from Figure $8 \mathrm{c}$ that the $C L R$ maintains a relatively stable decrease when $d_{3}$ increases from 1.30 to $1.70 \mu \mathrm{m}$ in the whole wavelength range of $1.3 \sim 1.8 \mu \mathrm{m}$. In addition, we also find that the larger the $d_{3}$, the smaller the difference between the minimum and maximum $C L R$. When $d_{3}$ is $1.70 \mu \mathrm{m}$, the minimum and maximum of the CLR are 2.2541 and 1.9409 , respectively, and the difference between them is only 0.3132 .

(a)

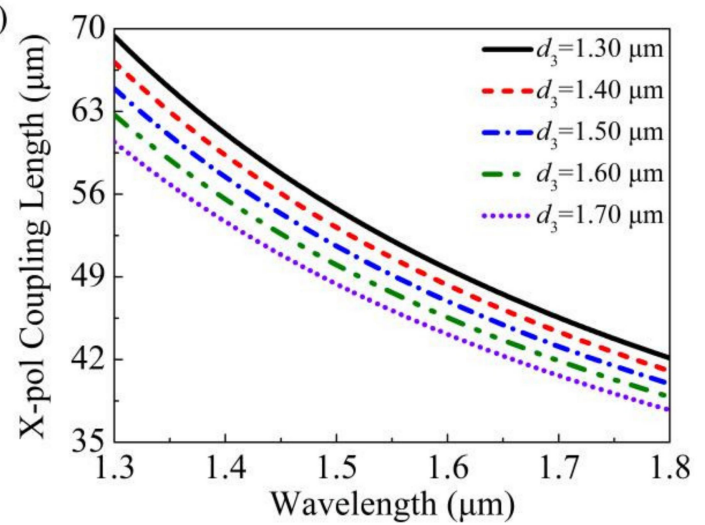

(b)

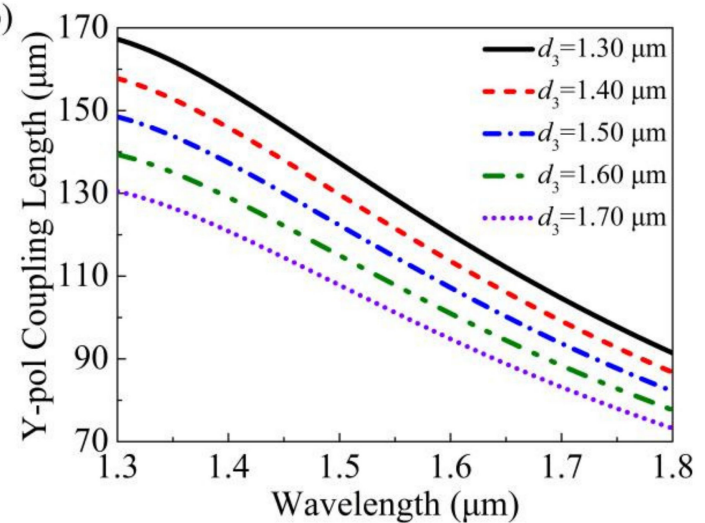

(c)

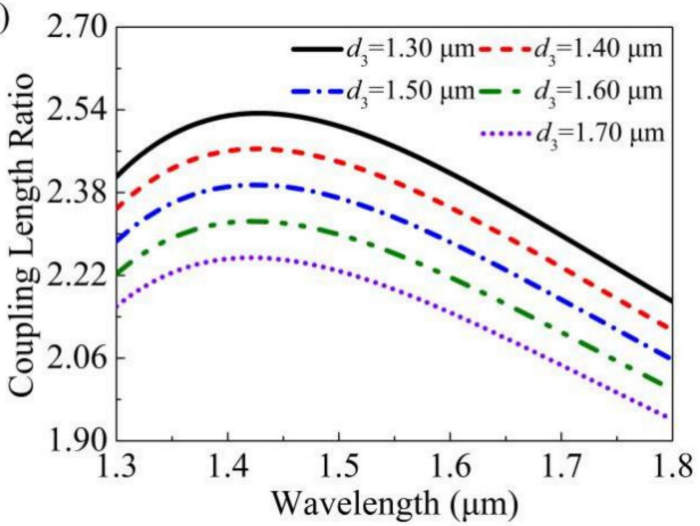

Figure 8. The change rules of the (a) $C L_{X},(\mathbf{b}) C L_{Y}$, and (c) $C L R$ of the LC-DC-PCF with wavelengths for different $d_{3}$.

The change rules of the $C L_{X}, C L_{Y}$, and $C L R$ of the proposed LC-DC-PCF with wavelengths for different $d_{4}$ are shown in Figure 9a-c. From Figure 9a,b, the $C L_{X}$ and $C L_{Y}$ gradually decrease when $d_{4}$ increases from 1.40 to $1.80 \mu \mathrm{m}$ in the whole wavelength range of 1.3 1.8 $\mu \mathrm{m}$. The decreasing amplitude of the $C L_{X}$ and $C L_{Y}$ is nearly the same. Therefore, as shown in Figure $9 \mathrm{c}$, the $C L R$ has a small change when $d_{4}$ increases from 1.40 to $1.80 \mu \mathrm{m}$ in the whole wavelength range of $1.3 \sim 1.8 \mu \mathrm{m}$. In addition, when $d_{4}$ is $1.40 \mu \mathrm{m}$ and $1.8 \mu \mathrm{m}$, the minimum and maximum of the CLR are 2.0436, 2.3835, and 2.0653, 2.3996, respectively. The maximum difference of the CLR is only 0.0217 .

The change rules of the $C L_{X}, C L_{Y}$, and $C L R$ of the proposed LC-DC-PCF with wavelengths for different $d_{5}$ are shown in Figure 10a-c. From Figure 10a,b, the curves under different $d_{5}$ are virtually coincident, that is to say, the $C L_{X}$ and $C L_{Y}$ do not change when $d_{5}$ increases from 1.40 to $1.80 \mu \mathrm{m}$ in the whole wavelength range of $1.3 \sim 1.8 \mu \mathrm{m}$. Certainly, the CLR will not change with the change of $d_{5}$ in the whole wavelength range of $1.3 \sim 1.8 \mu \mathrm{m}$. 
(a)

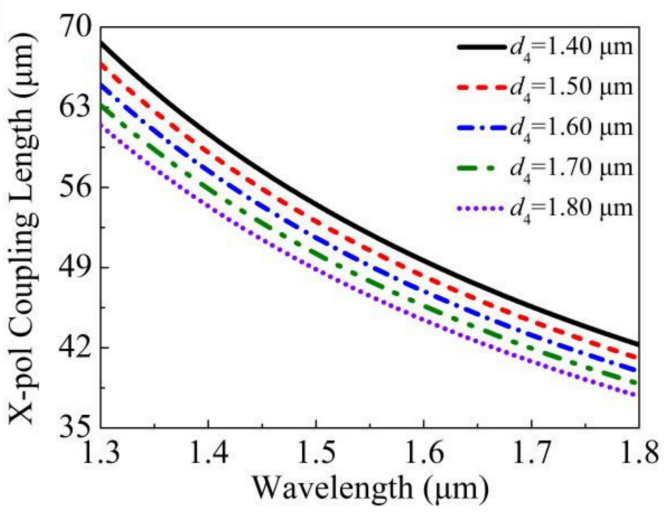

(b)

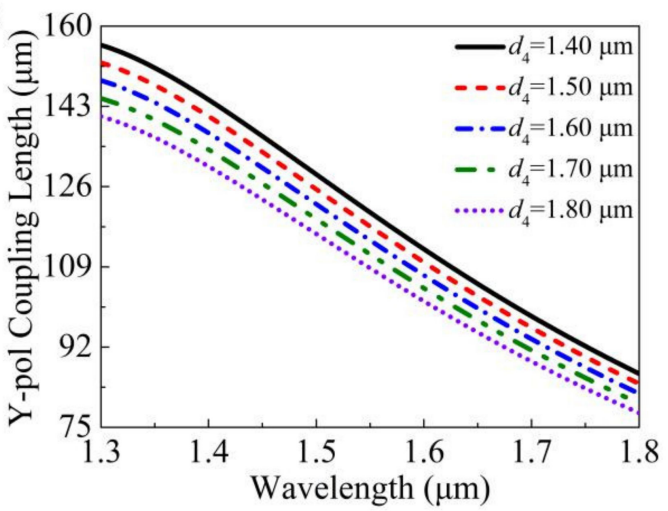

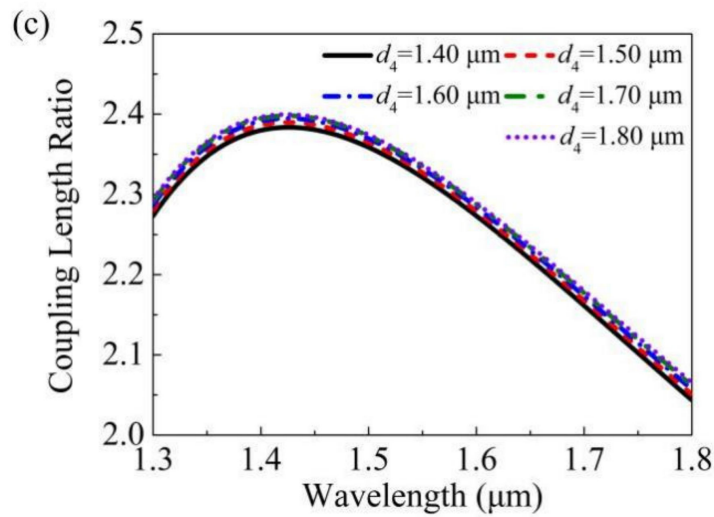

Figure 9. The change rules of the (a) $C L_{X},(\mathbf{b}) C L_{Y}$, and (c) CLR of the LC-DC-PCF with wavelengths for different $d_{4}$.

(a)

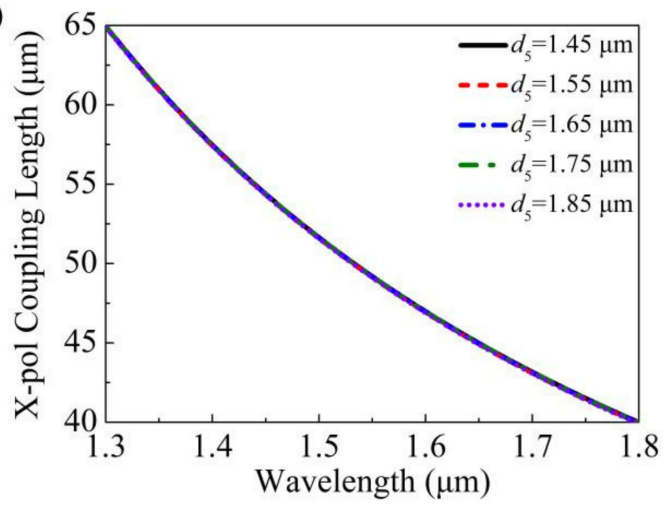

(b)

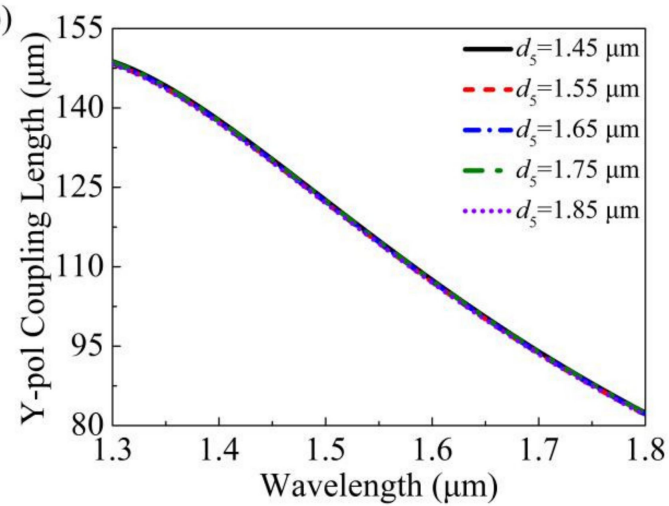

(c)

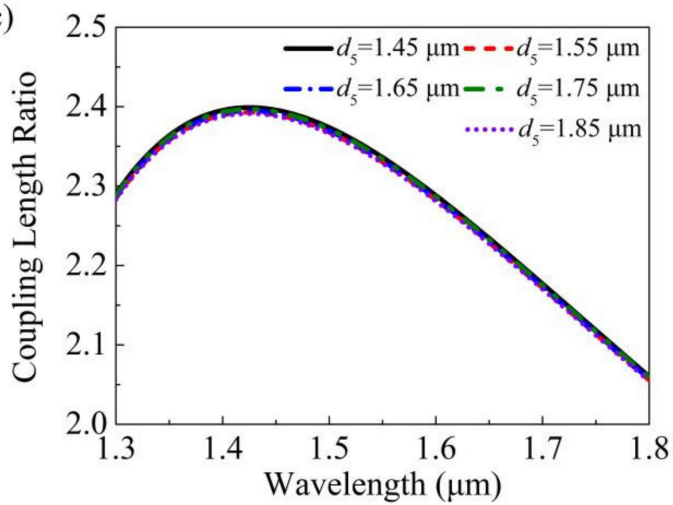

Figure 10. The change rules of the (a) $C L_{X}$, (b) $C L_{Y}$, and (c) $C L R$ of the LC-DC-PCF with wavelengths for different $d_{5}$. 
The change rules of the $C L_{X}, C L_{Y}$, and CLR of the proposed LC-DC-PCF with wavelengths for different $\Lambda$ are shown in Figure 11a-c. From Figure 11a it can be seen that the $C L_{X}$ increases gradually in the whole wavelength range of $1.3 \sim 1.8 \mu \mathrm{m}$ when $\Lambda$ increases from 1.90 to $2.30 \mu \mathrm{m}$. From Figure 11b, although the $C L_{Y}$ also increases gradually in the whole wavelength range of $1.3 \sim 1.8 \mu \mathrm{m}$ when $\Lambda$ increases from 1.90 to $2.30 \mu \mathrm{m}$, the increasing amplitude of the $C L_{Y}$ is larger at the shorter wavelength and smaller at the longer wavelength. Hence, when $\Lambda$ increases from 1.90 to $2.30 \mu \mathrm{m}$, the CLR increases gradually, but the increased amplitude of the CLR is larger at the shorter wavelength and smaller at the longer wavelength. When $\Lambda$ is $1.90 \mu \mathrm{m}$, the maximum and minimum of the CLR are 2.0778 and 1.9035 , respectively, and the difference between them is only 0.1743 . When $\Lambda$ is $2.30 \mu \mathrm{m}$, the maximum and minimum of the CLR are 2.2349 and 2.8137, respectively, and the difference between them can reach 0.5877 . That is to say, the difference between the maximum and minimum of the $C L R$ becomes larger when $\Lambda$ increases from 1.90 to $2.30 \mu \mathrm{m}$.

(a)

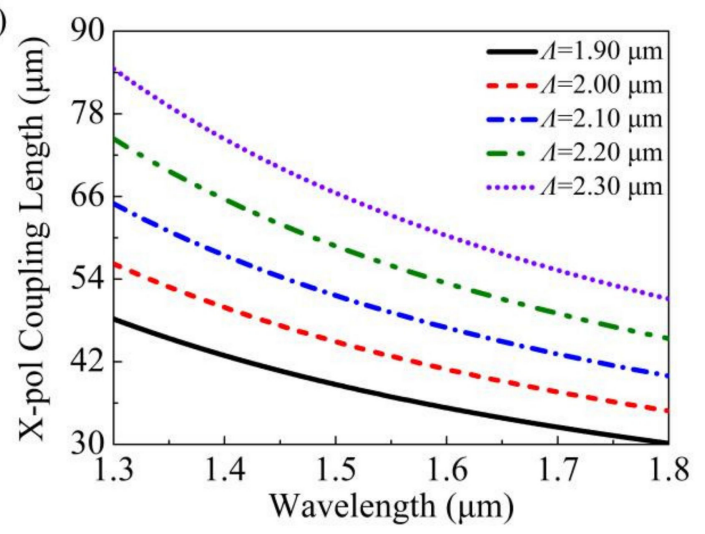

(b)

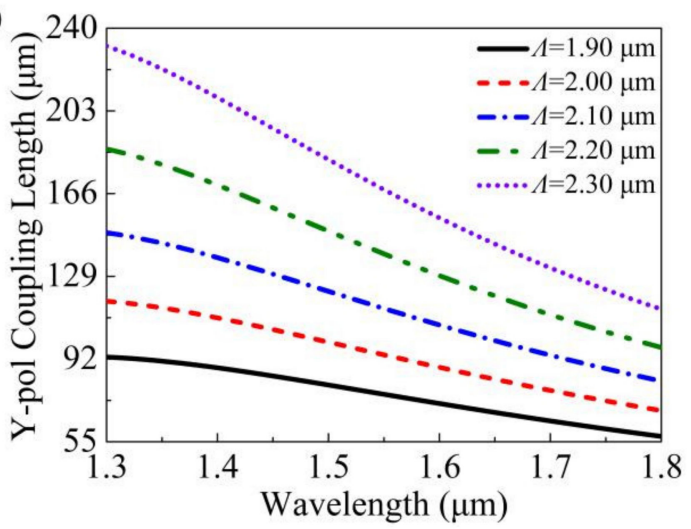

(c)

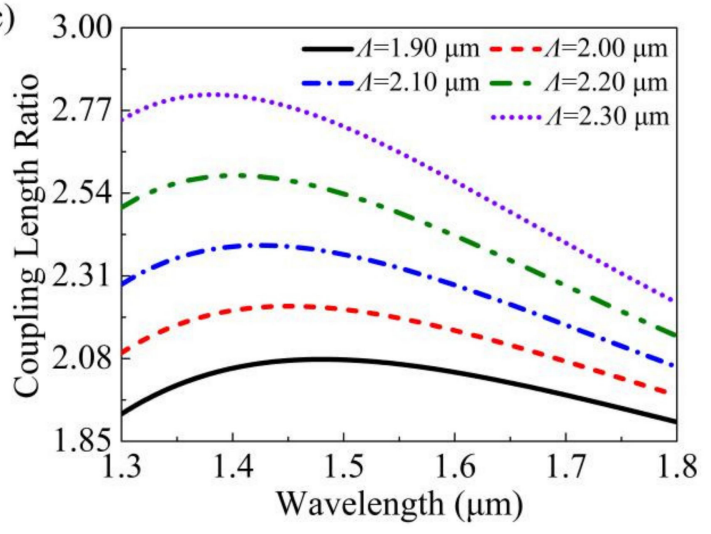

Figure 11. The change rules of the (a) $C L_{X},(\mathbf{b}) C L_{Y}$, and (c) $C L R$ of the LC-DC-PCF with wavelengths for different $\Lambda$.

\section{Discussion}

According to the above analysis, considering the influences of structural parameters on the $C L_{X}, C L_{Y}$, and CLR of the proposed LC-DC-PCF, a set of final parameters is set as $d_{1}=1.00 \mu \mathrm{m}, d_{2}=0.90 \mu \mathrm{m}, d_{3}=1.50 \mu \mathrm{m}, d_{4}=1.65 \mu \mathrm{m}, d_{5}=1.70 \mu \mathrm{m}$, and $\Lambda=2.10 \mu \mathrm{m}$. The relationships of the CLX,CLY, and CLR of the proposed LC-DC-PCF with wavelengths obtained under the final parameters are shown in Figure 12. From Figure 12, the $C L_{X}$ decreases with the increase in wavelength, while the $C L_{Y}$ first increases and then decreases with the increase in wavelength. At the same time, we notice that the $C L_{X}$ and $C L_{Y}$ have a relatively small length, and the maximum length is only $98.4 \mu \mathrm{m}$. With the increase in wavelength, the CLR first presents a gradual upward trend, but the upward trend gradually decreases and finally has a nearly flat change. When the wavelength is equal to $1.604 \mu \mathrm{m}$, 
the CLR is equal to 2. Before the wavelength of $1.604 \mu \mathrm{m}$, the range of the CLR change is 1.22 2.0. After the wavelength of $1.604 \mu \mathrm{m}$, the range of the CLR change is only 2.0 2.036.

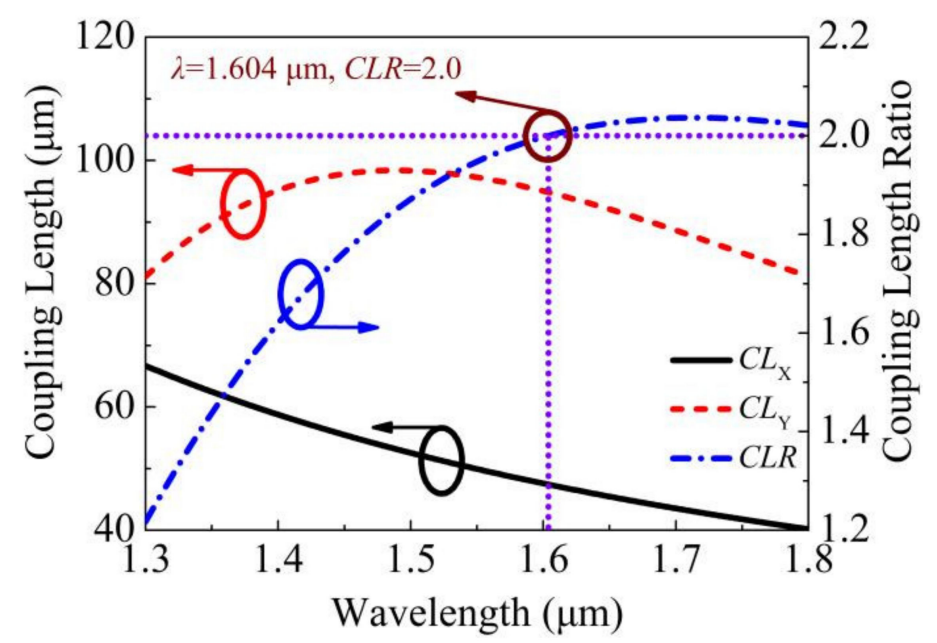

Figure 12. The relationships of the $C L_{X}, C L_{Y}$, and CLR of the proposed LC-DC-PCF with wavelengths.

We mentioned earlier that, when the $C L R=2$ and the $C L_{X}$ and $C L_{Y}$ are shorter, the proposed PBS is easier to obtain the shortest $L_{S}$. Therefore, the relationships between the Xpol and Y-pol $P_{\text {out }}$ in the core A of the proposed LC-DC-PCF PBS and $L_{P}$ at the wavelength of $1.604 \mu \mathrm{m}$ are shown in Figure 13. From Figure 13, when the $L_{P}$ is $0 \mu \mathrm{m}, P_{\text {out }}$ of the X-pol and Y-pol is the maximum because the initial incident light enters the core A. When $L_{P}$ is $94 \mu \mathrm{m}, P_{\text {out }}$ of the $\mathrm{X}$-pol reaches the maximum again, while $P_{\text {out }}$ of the Y-pol reaches 0 for the first time. This shows that only X-pol light exists in core A, and Y-pol light only exists in core B. When $L_{\mathrm{P}}$ is $188 \mu \mathrm{m}, P_{\text {out }}$ of the X-pol and Y-pol is once again maximum. It indicates that both the X-pol and Y-pol light completely exist in core A again, just as in the initial incident. That is enough to show that $P_{\text {out }}$ of the $X$-pol and Y-pol changes periodically with the increase in $L_{P}$. That is to say, the $X$-pol and Y-pol light propagate periodically in cores A and B. When the X-pol and Y-pol light are separated to cores A and B for the first time, respectively, the corresponding $L_{\mathrm{P}}=94 \mu \mathrm{m}$ is the shortest $L_{\mathrm{S}}$.

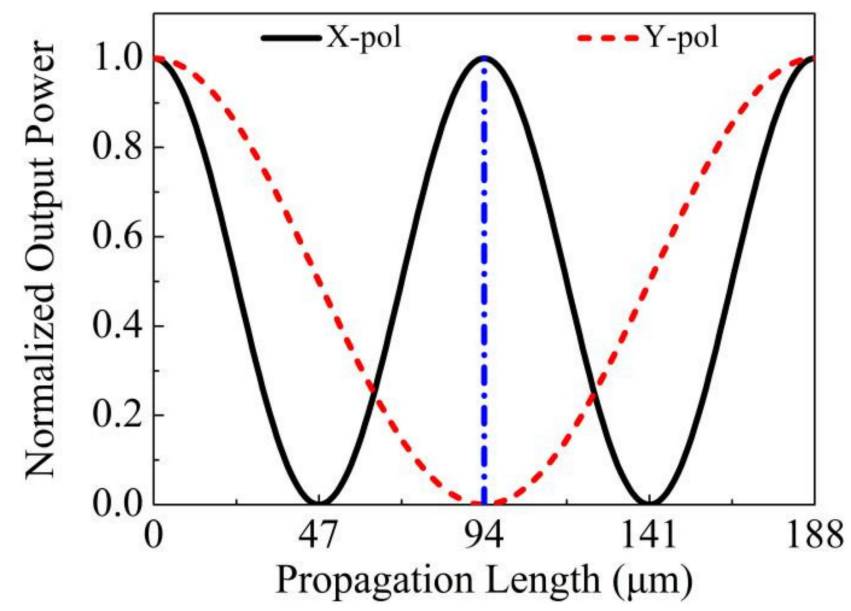

Figure 13. The relationships between the X-pol and Y-pol $P_{\text {out }}$ in the core A of the proposed LC-DCPCF PBS and the $L_{\mathrm{P}}$ at $1.604 \mu \mathrm{m}$.

When $L_{\mathrm{P}}$ is $94 \mu \mathrm{m}$, the relationship of the ER in the core A of the proposed LC-DC-PCF with wavelengths is shown in Figure 14. It can be seen from Figure 14 that with the increase in wavelength, the $E R$ first increases and then reaches the first maximum peak value of $60.3 \mathrm{~dB}$ at the wavelength of $1.386 \mu \mathrm{m}$. Then, as the wavelength continues to increase, 
the $E R$ first decreases and then increases; a relatively gentle $E R$ valley is formed between 1.386 and $1.619 \mu \mathrm{m}$, and then reaches the second maximum peak value of $72.2 \mathrm{~dB}$ at the wavelength of $1.619 \mu \mathrm{m}$. After $1.619 \mu \mathrm{m}$, the $E R$ decreases gradually with the increase in wavelength. Between 1.352 and $1.701 \mu \mathrm{m}$, the $E R$ is greater than $20 \mathrm{~dB}$. In other words, the splitting bandwidth of the proposed LC-DC-PCF PBS can reach $349 \mathrm{~nm}(1.352 \sim 1.701 \mu \mathrm{m})$, which can cover the whole of the $\mathrm{E}+\mathrm{S}+\mathrm{C}+\mathrm{L}+\mathrm{U}$ communication bands.

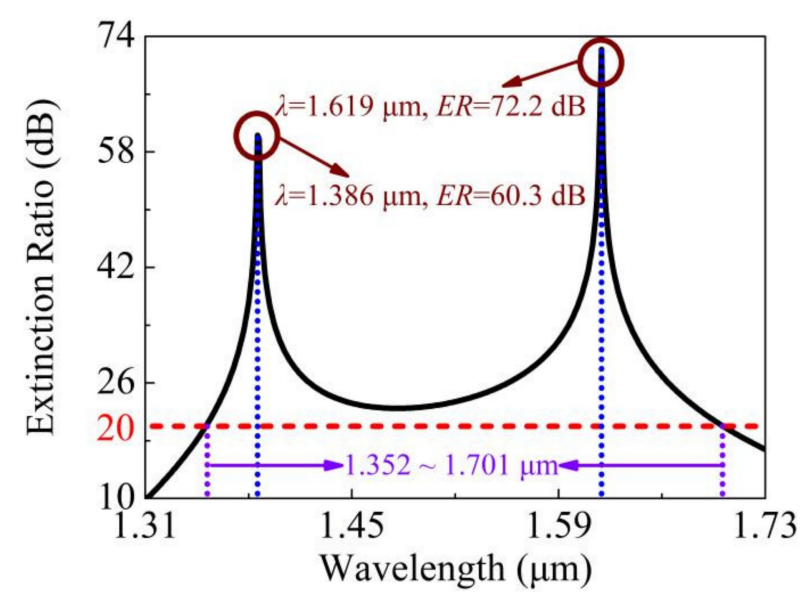

Figure 14. The relationship of the ER in the core A of the proposed LC-DC-PCF with wavelengths.

The comparisons between the proposed LC-DC-PCF PBS and reported DC-PCF PBS are shown in Table 1. From Table 1, since the cost of liquid crystal E7 is significantly lower than that of gold, from the perspective of structural fabrication and cost reduction, the proposed LC-DC-PCF PBS in this work is only filling liquid crystal E7 in one air hole, does not fill other materials, and does not contain elliptical air holes, which not only reduces the fabrication difficulty but also reduces the fabrication cost. In addition, only $L_{\mathrm{S}}$ of the DC-PCF PBS reported in Ref. [27] is slightly shorter than that of the proposed LC-DC-PCF PBS, but the splitting bandwidth of the proposed LC-DC-PCF PBS is more than ten times that of the DC-PCF PBS reported in Ref. [27]. Moreover, the maximum ER of the DC-PCF PBS reported in Refs. $[16,38,39]$ is slightly higher than that of the proposed LC-DC-PCF PBS, but the proposed LC-DC-PCF PBS has the widest splitting bandwidth and the shortest $L_{\mathrm{S}}$ compared with other results reported in Refs. $[16,38,39]$. Because the splitting bandwidth of the DC-PCF PBS is the wavelength range corresponding to the $E R$ greater than $20 \mathrm{~dB}$, even if the maximum ER of a certain wavelength is large, the final splitting bandwidth is not necessarily the widest, so it is only necessary to compare the $L_{S}$ and splitting bandwidth. To summarize, it can be seen that the proposed LC-DC-PCF PBS in this work can obtain a shorter $L_{S}$ and wider splitting bandwidth at the same time and has a lower cost and simpler fabrication process.

Table 1. Comparisons between the proposed LC-DC-PCF PBS and reported DC-PCF PBS.

\begin{tabular}{ccccc}
\hline Ref. & Structural Characteristics & Splitting Bandwidth & $L_{\mathbf{S}}$ & Max ER \\
\hline$[16]$ & Filling liquid crystal E7 in one air hole & $250 \mathrm{~nm}$ & $175 \mu \mathrm{m}$ & $80.7 \mathrm{~dB}$ \\
{$[24]$} & Filling liquid crystal E7 in all air holes & $150 \mathrm{~nm}$ & $890.5 \mu \mathrm{m}$ & $45 \mathrm{~dB}$ \\
{$[25]$} & Filling liquid crystal E7 in six air holes & $88 \mathrm{~nm}$ & $111.2 \mu \mathrm{m}$ & $55 \mathrm{~dB}$ \\
and filling As $\mathrm{S}_{3}$ in one air hole & $3 \mathrm{~nm}$ & $5678 \mu \mathrm{m}$ & $<30 \mathrm{~dB}$ \\
{$[26]$} & Filling liquid crystal E7 in six air holes & $32.1 \mathrm{~nm}$ & $83.9 \mu \mathrm{m}$ & $44.05 \mathrm{~dB}$ \\
{$[27]$} & Filling liquid (ethanol) in six air holes and & $70 \mathrm{~nm}$ & $1079 \mu \mathrm{m}$ & $174.92 \mathrm{~dB}$ \\
{$[38]$} & filling Ti in two air holes & $318 \mathrm{~nm}$ & $188 \mu \mathrm{m}$ & $<82 \mathrm{~dB}$ \\
{$[39]$} & Filling elliptical gold wire in one air hole & $250 \mathrm{~nm}$ & $577.5 \mu \mathrm{m}$ & $42 \mathrm{~dB}$ \\
{$[40]$} & Coating gold film in one air hole & $349 \mathrm{~nm}$ & $94 \mu \mathrm{m}$ & $72.2 \mathrm{~dB}$ \\
\hline This work & Filling silver wire in one air hole & Filling liquid crystal E7 in one air hole &
\end{tabular}


The fabrication methods of the PCF mainly include the stack-and-draw method, femtosecond laser drilling method, 3D-printing method, etc., [3,43-45]. In addition, the technology of selectively filling LC in some or all of the air holes has also been very mature; in the past three years, there have been many reports on the practical fabrication of PCFs selectively filled with LC material [46-50]. In this work, the fabrication steps of the proposed LC-DC-PCF are as follows: first, the proposed LC-DC-PCF is fabricated by the stack-and-draw method. With this method, the high-purity silica glass tubes of different diameters and wall thicknesses are arranged according to the designed structure. Two high-purity silica solid rods with the same diameter are used to replace the high-purity silica glass tubes on the left and right sides of the most central high-purity silica glass tubes, respectively, to form the LC-DC-PCF preform, and then the LC-DC-PCF preform is drawn into the designed LC-DC-PCF. In the fabrication process, parameters such as temperature, air pressure, and traction speed must be controlled simultaneously to obtain the LC-DC-PCF with an excellent final structure. Finally, the LC E7 is selectively filled in the central air hole of the proposed LC-DC-PCF by femtosecond laser-assisted selective infiltration technology. Among them, the technology mainly includes several steps, such as UV curable, normal splicing, laser cutting, capillary infiltration, etc.

In the actual fabrication process for the proposed LC-DC-PCF, some unnecessary tolerances will inevitably occur in the diameter of the air hole, which will lead to a $\pm 1 \%$ change in the final $L_{S}$. When the final $L_{S}$ changes $\pm 1 \%$, the relationships of the $E R$ in the core A of the proposed LC-DC-PCF with wavelength are shown in Figure 15. From Figure 15 , when the final $L_{S}$ changes $-1 \%$ and $+1 \%$, the wavelength ranges with $E R$ greater than $20 \mathrm{~dB}$ are 1.346 1.713 $\mu \mathrm{m}$ and 1.357 1.689 $\mu \mathrm{m}$, respectively, which can cover the whole of the $\mathrm{E}+\mathrm{S}+\mathrm{C}+\mathrm{L}+\mathrm{U}$ communication band. This indicates that the proposed LC-DC-PCF has good fabrication fault tolerance.

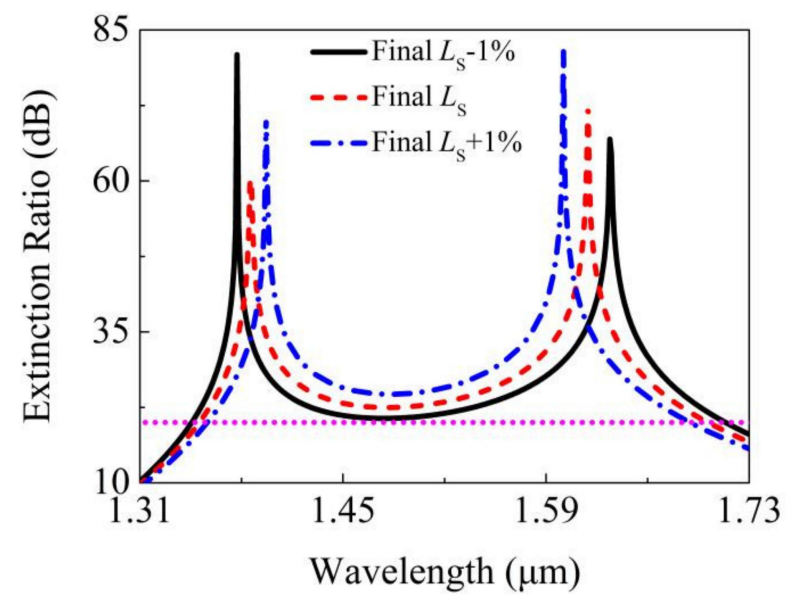

Figure 15. The relationship of the ER in the core A of the proposed LC-DC-PCF with wavelengths when the final $L_{S}$ changes $\pm 1 \%$.

\section{Conclusions}

In summary, a novel LC-DC-PCF PBS based on the DC-PCF-coupled mode theory is proposed. Using the FV-FEM, the effective refractive indices of the X-pol and Y-pol even and odd modes, the $B_{\mathrm{e}}$ and $B_{\mathrm{O}}$, the $C L_{\mathrm{X}}, C L_{Y}$, and CLR of the LC-DC-PCF filled without and with LC E7 are analyzed and compared. By optimizing the influences of cladding microstructure parameters on the $C L_{X}, C L_{Y}$, and CLR of the LC-DC-PCF, the CLR is exactly equal to 2 at a wavelength of $1.604 \mu \mathrm{m}$. The relationships between the X-pol and Y-pol $P_{\text {out }}$ in core A of the proposed LC-DC-PCF PBS and $L_{\mathrm{P}}$ at the wavelength of $1.604 \mu \mathrm{m}$ are investigated. The ERs in core A achieve 60.3 and $72.2 \mathrm{~dB}$ at wavelengths 1.386 and $1.619 \mu \mathrm{m}$, respectively. The final $L_{S}$ is $94 \mu \mathrm{m}$, and the splitting bandwidth can reach $349 \mathrm{~nm}$ $(1.352 \sim 1.701 \mu \mathrm{m})$, covering the whole of the $\mathrm{E}+\mathrm{S}+\mathrm{C}+\mathrm{L}+\mathrm{U}$ communication bands. The 
proposed LC-DC-PCF PBS has an ultra-short $L_{S}$ and ultra-wide splitting bandwidth, so it can be applied in laser, sensing, and communication systems.

Author Contributions: Conceptualization, Y.Q.; methodology, Y.Q. and Y.H.; software, Y.Q.; validation, J.Y.; formal analysis, Y.Q., Y.H. and J.Y.; investigation, Y.Q.; resources, Y.H. and J.Y.; data curation, Y.Q. and Y.H.; writing—original draft preparation, Y.Q.; writing—review and editing, Y.H. and J.Y.; visualization, X.Z. and B.Y.; supervision, K.W., X.S., and C.Y.; project administration, X.Z. and B.Y.; funding acquisition, J.Y. All authors have read and agreed to the published version of the manuscript.

Funding: This research was funded by the National Key Research and Development Project of China (2019YFB2204001), Program of the Natural Science Foundation of Hebei Province (F2021203002), and the Important Research Project of Hebei Province Application Foundation Plan (17961701D).

Institutional Review Board Statement: Not applicable.

Informed Consent Statement: Not applicable.

Data Availability Statement: Not applicable.

Acknowledgments: We thank the State Key Laboratory of Information Photonics and Optical Communications (Beijing University of Posts and Telecommunications of China) for the scientific helps and supports throughout this research.

Conflicts of Interest: The authors declare no conflict of interest.

\section{References}

1. Knight, J.C.; Birks, T.A.; Russell, P.S.J.; Atkin, D.M. All-silica single-mode optical fiber with photonic crystal cladding. Opt. Lett. 1996, 21, 1547-1549. [CrossRef]

2. $\quad$ Birks, T.A.; Knight, J.C.; Russell, P.S.J. Endlessly single-mode photonic crystal fiber. Opt. Lett. 1997, 22, 961-963. [CrossRef]

3. Knight, J.C.; Broeng, J.; Birks, T.A.; Russell, P.S.J. Photonic band gap guidance in optical fibers. Science 1998, 282, 1476-1478. [CrossRef]

4. Islam, R.; Habib, M.S.; Hasanuzzaman, G.K.M.; Ahmad, R.; Rana, S.; Kaijage, S.F. Extremely high-birefringent asymmetric slotted-core photonic crystal fiber in THz regime. IEEE Photon. Technol. Lett. 2015, 27, 2222-2225. [CrossRef]

5. Xu, Z.L.; Lim, J.L.; Hu, D.J.J.; Sun, Q.Z.; Wong, R.Y.N.; Li, K.; Jiang, M.; Shum, P.P. Investigation of temperature sensing characteristics in selectively infiltrated photonic crystal fiber. Opt. Express 2016, 24, 1699-1707. [CrossRef]

6. Hu, D.J.J.; Ho, H.P. Recent advances in plasmonic photonic crystal fibers: Design, fabrication and applications. Adv. Opt. Photonics 2017, 9, 257-314. [CrossRef]

7. Mollaha, M.S.; Yousufalia, M.; Rifat Bin Asif Faysala, M.; Rabiul Hasanb, M.; Biplob Hossainc, M.; Amiri, I.S. Highly sensitive photonic crystal fiber salinity sensor based on Sagnac interferometer. Results Phys. 2020, 16, 103022. [CrossRef]

8. Maidi, A.M.; Abas, P.E.; Petra, P.I.; Kaijage, S.; Zou, N.Y.; Begum, F. Theoretical considerations of photonic crystal fiber with all uniform-sized air holes for liquid sensing. Photonics 2021, 8, 249. [CrossRef]

9. Paul, A.K.; Mollah, M.A.; Hassan, M.Z.; Gomez-Cardona, N.; Reyes-Vera, E. Graphene-coated highly sensitive photonic crystal fiber surface plasmon resonance sensor for aqueous solution: Design and numerical analysis. Photonics 2021, 8, 155. [CrossRef]

10. Haider, F.; Aoni, R.A.; Ahmed, R.; Chew, W.J.; Mahdiraji, G.A. Plasmonic micro-channel based highly sensitive biosensor in visible to mid-IR. Opt. Laser Technol. 2021, 140, 107020. [CrossRef]

11. Wang, K.; Qu, Y.W.; Yuan, J.H.; Qiu, S.; Zhou, X.; Yan, B.B.; Wu, Q.; Liu, B.; Wang, K.R.; Sang, X.Z.; et al. Ultra-short polarization beam splitter based on dual-core photonic crystal fiber with surface plasmon resonance effect. Opt. Eng. 2021, 60, 076104. [CrossRef]

12. Wang, C.L.; Shum, P.P.; Hu, D.J.J.; Chen, Y.C.; Xu, Z.L.; Liu, S.H.; Zhang, Y.N.; Zhu, Y.W.; Zheng, Y.; Li, B.C.; et al. Two-core photonic crystal fiber with selective liquid infiltration in the central air hole for temperature sensing. OSA Contin. 2020, 3, 2264-2276. [CrossRef]

13. Zhang, Y.X.; Qu, Y.W.; Yuan, J.H.; Wang, H.Y.; Zhou, X.; Huo, J.H.; Yan, B.B.; Wu, Q.; Wang, K.R.; Sang, X.Z.; et al. Polarization beam splitter based on the gold wire-filled dual-core photonic crystal fiber at the communication wavelengths. Fiber Integr. Opt. 2021, 40, 1-14. [CrossRef]

14. Qiu, S.; Yuan, J.H.; Zhou, X.; Qu, Y.W.; Yan, B.B.; Wu, Q.; Wang, K.R.; Sang, X.Z.; Long, K.P.; Yu, C.X. Highly sensitive temperature sensing based on all-solid cladding dual-core photonic crystal fiber filled with the toluene and ethanol. Opt. Commun. 2020, 477, 126357. [CrossRef]

15. Qu, Y.W.; Yuan, J.H.; Zhou, X.; Feng, L.; Yan, B.B.; Wu, Q.; Wang, K.R.; Sang, X.Z.; Long, K.P.; Yu, C.X. Surface plasmon resonance-based silicon dual-core photonic crystal fiber polarization beam splitter at the mid-infrared spectral region. J. Opt. Soc. Am. B 2020, 37, 2221-2230. [CrossRef]

16. Chen, H.L.; Li, S.G.; Fan, Z.K.; An, G.W.; Li, J.S.; Han, Y. A novel polarization splitter based on dual-core photonic crystal fiber with a liquid crystal modulation core. IEEE Photo. J. 2014, 6, 2201109. [CrossRef] 
17. Hameed, M.F.O.; Balat, R.T.; Heikal, A.M.; Abo-Elkhier, M.M.; Abo el Maaty, M.I.; Obayya, S.S.A. Polarization-independent surface plasmon liquid crystal photonic crystal multiplexer-demultiplexer. IEEE Photo. J. 2015, 7, 4801110. [CrossRef]

18. Zi, J.C.; Li, S.G.; Wang, G.Y.; An, G.W.; Fan, Z.K. Design of ultra-short polarization beam splitter based on liquid-filled photonic crystal fiber. Opt. Quant. Electron. 2016, 48, 233. [CrossRef]

19. Wang, J.S.; Pei, L.; Weng, S.J.; Wu, L.Y.; Ning, T.G.; Li, J. Ultrashort polarization beam splitter based on liquid-filled dual-core photonic crystal fiber. Appl. Opt. 2018, 57, 3847-3852. [CrossRef]

20. Wang, H.Y.; Yan, X.; Li, S.G.; Zhang, X.N. Tunable surface plasmon resonance polarization beam splitter based on dual-core photonic crystal fiber with magnetic fluid. Opt. Quant. Electron. 2017, 49, 368. [CrossRef]

21. Wang, J.S.; Pei, L.; Weng, S.J.; Wu, L.Y.; Huang, L.; Ning, T.G.; Li, J. A tunable polarization beam splitter based on magnetic fluids-filled dual-core photonic crystal fiber. IEEE Photo. J. 2017, 9, 2200410. [CrossRef]

22. Jiang, L.H.; Zheng, Y.; Hou, L.T.; Zheng, K.; Peng, J.Y.; Zhao, X.T. An ultrabraoadband polarization splitter based on square-lattice dualcore photonic crystal fiber with a gold wire. Opt. Commun. 2015, 351, 50-56. [CrossRef]

23. Li, P.; Zhao, J.L. Polarization-dependent coupling in gold-filled dual-core photonic crystal fibers. Opt. Express 2013, 21, 5232-5238. [CrossRef] [PubMed]

24. Wang, E.L.; Jiang, H.M.; Xie, K.; Chen, C.; Hu, Z.J. Polarization splitter based on dual core liquid crystal-filled holey fiber. J. Appl. Phys. 2016, 120, 114501. [CrossRef]

25. Hagras, E.A.A.; Heikal, A.M.; Hamed, M.F.O.; El-Azab, J.M.; El-Nozahi, A.M.; Obayya, S.S.A. Ultra compact soft glass liquid photonic crystal polarization splitter with $\mathrm{As}_{2} \mathrm{~S}_{3}$ core. Opt. Quant. Electron. 2017, 49, 55. [CrossRef]

26. Younis, B.M.; Heikal, A.M.; Hameed, M.F.O.; Obayya, S.S.A. Highly wavelength-selective asymmetric dual-core liquid photonic crystal fiber polarization splitter. J. Opt. Soc. Am. B 2018, 35, 1020-1028. [CrossRef]

27. Xu, Q.; Luo, W.L.; Li, K.; Copner, N.; Lin, S. Design of polarization splitter via liquid and Ti infiltrated photonic crystal fiber. Crystals 2019, 9, 103. [CrossRef]

28. Rahman, M.T.; Datto, S.; Sakib, M.N. Highly sensitive circular slotted gold-coatedmicro channel photonic crystal fiber basedplasmonic biosensor. OSA Contin. 2021, 4, 1808-1826. [CrossRef]

29. Qiu, S.; Yuan, J.H.; Zhou, X.; Feng, L.; Wang, Q.W.; Qu, Y.W.; Yan, B.B.; Wu, Q.; Wang, K.R.; Sang, X.Z.; et al. Hollow-core negative curvature fiber with high birefringence for low refractive index sensing based on surface plasmon resonance effect. Sensors 2020, 20, 6539. [CrossRef]

30. Hameed, M.F.O.; Heikal, A.M.; Younis, B.M.; Abdelrazzak, M.; Obayya, S.S.A. Ultra-high tunable liquid crystal-plasmonic photonic crystal fiber polarization filter. Opt. Express 2015, 23, 7007-7020. [CrossRef]

31. Jiang, L.H.; Zheng, Y.; Yang, J.J.; Hou, L.T.; Li, Z.H.; Zhao, X.T. An Ultra-broadband single polarization filter based on plasmonic photonic crystal fiber with a liquid crystal core. Plasmonics 2017, 12, 411-417. [CrossRef]

32. Bao, Y.J.; Li, S.G.; Zhang, W.; An, G.W.; Fan, Z.K. Designing of a polarization beam splitter for the wavelength of $1310 \mathrm{~nm}$ on dual-core photonic crystal fiber with high birefringence and double-zero dispersion. Chin. Phys. B 2014, 23, 104218. [CrossRef]

33. Snyder, A.W.; Love, J.D. Optical Waveguide Theory; Chapman\&Hall: London, UK, 1983; pp. 542-552.

34. Dou, C.; Jing, X.L.; Li, S.G.; Wu, J.J.; Wang, Q.B. A compact and low-loss polarization splitter based on dual-core photonic crystal fber. Opt. Quant. Electron. 2018, 50, 255. [CrossRef]

35. Jiang, H.M.; Wang, E.L.; Zhang, J.; Hu, L.; Mao, Q.P.; Li, Q.; Xie, K. Polarization splitter based on dual-core photonic crystal fiber. Opt. Express 2014, 22, 30461-30466. [CrossRef]

36. Zhang, Y.Z.; Liu, H.; Chen, C.; Bai, B.B.; Tang, S.F. Temperature-controlled and multi-functional splitter based on dual-core photonic crystal fiber. Results Phys. 2020, 19, 103578. [CrossRef]

37. Chu, L.H.; Liu, M.; Shum, P.; Fu, Y.B. Simultaneous achievement of an ultrashort length and a high extinction ratio polarization splitter based on the dual-core photonic crystal fiber with $\mathrm{Ge}_{20} \mathrm{Sb}_{15} \mathrm{Se}_{65}$ glass. Appl. Opt. 2019, 58, 7892-7896. [CrossRef]

38. Wang, X.Y.; Li, S.G.; Liu, Q.; Fan, Z.K.; Wang, G.Y.; Zhao, Y.Y. High-extinction ratio and short-length polarization splitter based on microstructured optical fiber with tellurite glass. Opt. Mater. 2017, 66, 542-546. [CrossRef]

39. Qu, Y.W.; Yuan, J.H.; Qiu, S.; Zhou, X.; Feng, L.; Yan, B.B.; Wu, Q.; Wang, K.R.; Sang, X.Z.; Long, K.P.; et al. A novel gold film-coated V-shape dual-core photonic crystal fiber polarization beam splitter covering the E + S $+\mathrm{C}+\mathrm{L}+\mathrm{U}$ band. Sensors 2021, 21, 496. [CrossRef]

40. Sun, B.; Chen, M.Y.; Zhang, Y.K.; Zhou, J. Polarization-dependent coupling characteristics of metal-wire filled dual-core photonic crystal fiber. Opt. Quant. Electron. 2015, 47, 441-451. [CrossRef]

41. Zou, H.; Xiong, H.; Zhang, Y.S.; Ma, Y.; Zheng, J.J. Ultra-broadband polarization splitter based on graphene layer-filled dual-core photonic crystal fiber. Chin. Phys. B 2017, 26, 124216. [CrossRef]

42. Zhao, Y.Y.; Li, S.G.; Wang, X.Y.; Wang, G.Y.; Shi, M.; Wu, J.J. Design of a novel multi channel photonic crystal fiber polarization beam splitter. Opt. Commun. 2017, 400, 79-83. [CrossRef]

43. Li, Y.; Itoh, K.; Watanabe, W.; Yamada, K.; Kuroda, D.; Nishii, J.; Jiang, Y.Y. Three-dimensional hole drilling of silica glass from the rear surface with femtosecond laser pulses. Opt. Lett. 2001, 26, 1912-1914. [CrossRef] [PubMed]

44. Bertoncini, A.; Liberale, C. 3D printed waveguides based on photonic crystal fiber designs for complex fiber-end photonic devices. Optica 2020, 7, 1487-1494. [CrossRef]

45. Feng, X.; Mairaj, A.K.; Hewak, D.W.; Monro, T.M. Nonsilica glasses for holey fibers. J. Lightw. Technol. 2005, 23, 2046-2054. [CrossRef] 
46. Huang, Y.J.; Wang, Y.; Zhang, L.F.; Shao, Y.; Zhang, F.; Liao, C.R.; Wang, Y.P. Tunable electro-optical modulator based on a photonic crystal fiber selectively filled with liquid crystal. J. Lightw. Technol. 2019, 37, 1903-1908. [CrossRef]

47. Lin, J.D.; Chiu, C.Y.; Mo, T.S.; Lee, C.R. All-optical directional control of emission in a photonic liquid crystal fiber laser. J. Lightw. Technol. 2020, 38, 5149-5156. [CrossRef]

48. Liu, Q.; Xue, P.S.; Wu, Q.; Zhao, C.Y.; Ng, W.P.; Fu, Y.Q.; Binns, R. Electrically sensing characteristics of the sagnac interferometer embedded with a liquid crystal-infiltrated photonic crystal fiber. IEEE Trans. Instrum. Meas. 2021, 70, 9511209.

49. Tian, S.; Yang, T.Y.; Zhang, J.X.; Xie, K.; Ma, J.J.; Hong, L.; Luo, Y.H.; Hu, Z.J. Multi-band thermal optical switch based on nematic liquid crystal filled photonic crystal fiber. J. Lightw. Technol. 2021, 39, 3297-3302. [CrossRef]

50. Li, Y.; Wang, L.N.; Chen, Y.Z.; Yi, D.; Teng, F.; Hong, X.M.; Li, X.J.; Geng, Y.F.; Shi, Y.; Luo, D. High-performance fiber sensor via Mach-Zehnder interferometer based on immersing exposed-core microstructure fiber in oriented liquid crystals. Opt. Express 2020, 28, 3576-3586. [CrossRef] 